\title{
Inhibitory effects of aesculetin on the proliferation of colon cancer cells by the Wnt/ $\beta$-catenin signaling pathway
}

\author{
$\mathrm{TAO} \mathrm{LI}^{1^{*}}$, LEI ZHANG ${ }^{2 *}$ and XINKAI HUO ${ }^{3}$ \\ Departments of ${ }^{1}$ Oncology, ${ }^{2}$ Proctology and ${ }^{3}$ Gastrointestinal Surgery, Dezhou People's Hospital, \\ Dezhou, Shandong 253014, P.R. China
}

Received August 3, 2017; Accepted January 25, 2018

DOI: $10.3892 / \mathrm{ol} .2018 .8244$

\begin{abstract}
The inhibitory effect of aesculetin on the growth of colon cancer cell line SW480 through the Wnt/ $\beta$-catenin signaling pathway was studied. The appropriate concentration of aesculetin was selected by cell counting kit-8 (CCK-8) assay, and the effect of aesculetin on the proliferation of SW480 cells was investigated by bromodeoxyuridine (BrdU) assay. The expression level of the messenger ribonucleic acid (mRNA) in $\beta$-catenin and Wnt signaling pathway target genes, c-Myc and cyclin D1, was detected by reverse transcription-polymerase chain reaction (RT-PCR). The expression levels of $\beta$-catenin, $c-M y c$ and cyclin D1 proteins were detected by western blotting. CCK-8 detection results showed that compared with the control group, aesculetin effectively inhibited the proliferation of SW480 cells. BrdU detection results indicated that the number of BrdU positive cells in all the groups treated with drugs was significantly decreased. The of RT-PCR results suggested that aesculetin reduced the expression level of $\beta$-catenin mRNA and inhibited the expression of mRNA in the Wnt signaling pathway target genes, $c$-Myc and cyclin D1. Western blotting detection results revealed that aesculetin downregulated the expression level of $\beta$-catenin, c-Myc and cyclin D1 proteins. Aesculetin can inhibit tumor growth by suppressing the Wnt signaling pathway. This study provides a new idea and direction for the antitumor mechanism of aesculetin.
\end{abstract}

\section{Introduction}

Colon cancer is a disease with a high incidence among malignant tumors globally, and its incidence rate ranks third

Correspondence to: Dr Xinkai Huo, Department of Gastrointestinal Surgery, Dezhou People's Hospital, 1751 Xinhu Street, Dezhou, Shandong 253014, P.R. China

E-mail: dezhouyy123@163.com

*Contributed equally

Key words: aesculetin, colon cancer cell line SW480, Wnt/ $\beta$-catenin signaling pathway, proliferation among malignant tumors in developed countries in Europe and America (1). At present, with the improvement of China's economic level and changes in living habits, dietary structure and lifestyle, the number of individuals suffering from colon cancer in China shows an increasing trend.

Colon cancer is a malignant disease, which is a malignant lesion not induced by a single factor but by a variety of genes and with complex mechanisms of action. It seriously threatens human health and the quality of life. However, colon cancer is characterized by slow progression and a high cure rate in the early stage. If effective interventions are conducted in the early stage, the 5-year survival rate may reach $90 \%$ (2). Therefore, if the pathogenesis of colon cancer can be effectively studied, and early screening and diagnosis carried out, the timely treatment of colon cancer, improvement of prognosis and the quality of life of patients would be significantly influenced. The study of Olaku and White (3) showed that traditional Chinese medicines and their active ingredients with obvious pharmacological activity can significantly inhibit the proliferation of cancer cells or induce cancer cell apoptosis with high efficiency and low toxicity reducing the adverse effects of chemotherapy drugs. Therefore, the active ingredients extracted from Chinese herbal medicines with antitumor activity are very important screening methods for antitumor drugs (4-6).

Aesculetin belongs to the natural coumarin compounds, and studies have shown that aesculetin can significantly inhibit the proliferation of melanoma cells, lung cancer cells, gastric cancer cells and other tumor cells (7-10).

This study aimed to investigate the relevant possible mechanisms in the process of growth and inhibition of human colonic cancer cell line SW480, which provides a basis for the clinical treatment of colon cancer using aesculetin.

\section{Materials and methods}

Materialsandreagents. Aesculetin,bromodeoxyuridine(BrdU) and 3-(4,5-dimethylthiazol-2-yl)-2,5-diphenyltetrazolium bromide (MTT) (Sigma-Aldrich, St. Louis, MO, USA); human colon cancer cell line SW480 (Cell Bank, Chinese Academy of Sciences, Shanghai, China); BrdU kit, rabbit anti-human glyceraldehyde 3-phosphate dehydrogenase (GAPDH; cat. no. 10494-1-AP), $\beta$-catenin (cat. no. 17565-1-AP), c-Myc (cat. no. 10828-1-AP) and cyclin D1 (cat. no. 60186-1-Ig) primary polyclonal antibodies and goat anti-rabbit horseradish 
peroxidase (HRP)-labeled secondary polyclonal antibody (cat. no. SA00001-2) (ProteinTech Group Inc., Wuhan, China); Dulbecco's modified Eagle's medium (DMEM; Gibco, Carlsbad, CA, USA); ribonucleic acid (RNA) extraction kits, reverse transcription kits, reverse transcription-polymerase chain reaction (RT-PCR) kits (Invitrogen, Carlsbad, CA, USA); primer synthesis (Takara, Dalian, China); and human immunization (Biotechnology Research Institute, Nantong, China), bicinchoninic acid (BCA) protein quantification kits and cell lysate (Beyotime Institute of Biotechnology, Nantong, China) were used in the present study.

Cell culture. Colon cancer SW480 cells were cultured in DMEM containing 10\% fetal bovine serum, amino acid and double-antibodies with $100 \mathrm{kU} / 1$ penicillin and $0.1 \%$ streptomycin in an incubator at $37^{\circ} \mathrm{C}, 5 \% \mathrm{CO}_{2}$ and saturated humidity. The cells were continuously subcultured, and the culture medium was regularly replaced. When the cells grew to $80 \%$ confluence, trypsin was used for digestion, and follow-up experiments were conducted.

Detection of the inhibition rate of cell proliferation by cell counting kit-8 (CCK-8) assay. Colon cancer SW480 cells in the logarithmic growth phase were used. After digestion, the cells were counted using a cell counter, and $100 \mu \mathrm{l}$ single cell suspension containing $1 \times 10^{5}$ cells was added to 96 -well plates. After cells adhered to the wall, the original culture medium was removed, and $100 \mu \mathrm{l}$ drugs at the corresponding concentration were added according to the experimental grouping. CCK-8 solution $(10 \mu \mathrm{l})$ was added to the 96 -well plates at 10,48 and $72 \mathrm{~h}$. After $4 \mathrm{~h}$, the optical density (OD) of each well at the wavelength of $450 \mathrm{~nm}$ was measured using a microplate reader (Bio-Rad Laboratories, Inc., Hercules, CA, USA). The inhibition rate was calculated as: (1-OD value of the experimental group/OD value of the blank control group) $\mathrm{x} 100 \%$.

Detection of cell proliferation by BrdU test. Cells $\left(2 \times 10^{5}\right)$ were inoculated in 24-well plates with the volume of $200 \mu \mathrm{l}$, and three control wells were set. The cells were incubated at $37^{\circ} \mathrm{C}$ with $5 \% \mathrm{CO}_{2}$ for $24 \mathrm{~h}$. After cells adhered to the wall, and the solution was replaced with serum-free medium, BrdU at the final concentration of $30 \mu \mathrm{g} / 1$ was added before the termination of culture, and $40 \mathrm{~min}$ later, the cells were fixed and added with mouse-derived BrdU monoclonal antibodies overnight after blocking by goat serum. Secondary antibodies were added, the anti-fluorescent quencher was added dropwise after the washing with phosphate-buffered saline (PBS), and the number of positive cells was observed under an inverted phase microscope.

Detection of the expression of $\beta$-catenin c-Myc and cyclin DI messenger ribonucleic acid ( $m R N A$ ) by RT-PCR. The cultured SW480 cells were inoculated in 6-well plates with $1 \times 10^{4} /$ well. After $24 \mathrm{~h}$, the supernatant was aspirated, and cells were cultured for $48 \mathrm{~h}$ in the culture medium containing $0.56,1.12$ and $2.24 \mathrm{mmol} / \mathrm{l}$ aesculetin, respectively. Cells were collected from each group, and the total RNA was extracted from tissues according to the protocol of the RNA extraction kit. The concentration and purity of the total RNA were detected by an ultraviolet-visible spectrophotometry (Hitachi, Tokyo,
Table I. Primer sequences of RT-qPCR.

\begin{tabular}{ll}
\hline Gene & \multicolumn{2}{c}{ Primer sequences } \\
\hline$\beta$-catenin & F: 5'-GCTTGGAATGAGACTGCTGA-3' \\
& R: 5'-CTGGCCATATCCACCAGAGT-3' \\
c-Myc & F: 5'-AGCGACTCTGAGGAGGAACA-3' \\
& R: 5'-TCCAGCAGAAGGTGATCCA-3' \\
Cyclin D1 & F: 5'-TGCCACAGATGTGAAGTTCATT-3' \\
& R: 5'-CAGTCCGGGTCACACTTGAT-3' \\
GAPDH & F: 5'-CAAGGTCATCCATGACAACTTTG-3' \\
& R: 5'-GTCCACCACCCTGTTGCTGTAG-3'
\end{tabular}

RT-PCR, reverse transcription-polymerase chain reaction; GAPDH, glyceraldehyde 3-phosphate dehydrogenase; F, forward; R, reverse.

Japan) (A260/A280 >1.8 results qualified). Complementary deoxyribonucleic acid (cDNA) was obtained from the reverse transcription according to the instructions of the reverse transcription kit. Then the expression of $\beta$-catenin, c-Myc and cyclin D1 mRNA was detected by RT-qPCR with cDNA as the template. Primer sequences are shown in Table I. Reaction conditions: at $95^{\circ} \mathrm{C}$ for $10 \mathrm{~min}$, at $95^{\circ} \mathrm{C}$ for $15 \mathrm{sec}$, at $60^{\circ} \mathrm{C}$ for $1 \mathrm{~min}$, and the amplification was for 40 cycles. The $\mathrm{Ct}$ value was calculated from the instrument software, and the relative expression was calculated using the $2^{-\Delta \mathrm{Cq}}$ method according to the following formula: $\Delta \mathrm{Cq}$ (target gene) $=\mathrm{Cq}$ (target gene)-Cq (control gene).

Detection of the expression of $\beta$-catenin, $c$-Myc and cyclin D1 proteins by western blotting. The cultured cells were inoculated in 6-well plates with $1 \times 10^{4} /$ well. After $24 \mathrm{~h}$, the supernatant was aspirated, and the cells were cultured for $48 \mathrm{~h}$ in the culture medium containing 0.56, 1.12 and $2.24 \mathrm{mmol} / 1$ aesculetin, respectively. Cells were collected from each group and lysed using cell lysates. The supernatant was collected after the centrifugation by a high-speed centrifugal machine at $8,000 \times \mathrm{g}$, at a low temperature for $15 \mathrm{~min}$. The concentration of extracted proteins was determined by the BCA kit.

Sodium dodecyl sulfate polyacrylamide gel electrophoresis (SDS-PAGE) was used to separate $50 \mu \mathrm{g}$ protein, and the isolated protein was transferred to polyvinylidene difluoride (PVDF) membranes. Proteins were sealed using blocking solution at room temperature for $1 \mathrm{~h}$, and incubated by primary antibodies $(1: 1,000)$ at $4^{\circ} \mathrm{C}$ overnight. After that, the secondary antibodies $(1: 2,000)$ were added for incubation at room temperature for $1 \mathrm{~h}$, and enhanced chemiluminescence (ECL) was used for development in the dark. The gel imager (Bio-Rad Laboratories, Hercules, CA, USA) was applied to scan records, and $G A D P H$ was taken as the internal reference for gray-scale analysis and comparison.

Statistical analysis. Data were expressed as mean \pm standard deviation and processed by Statistical Product and Service Solutions (SPSS) 17.0 (International Business Machines Corp., 


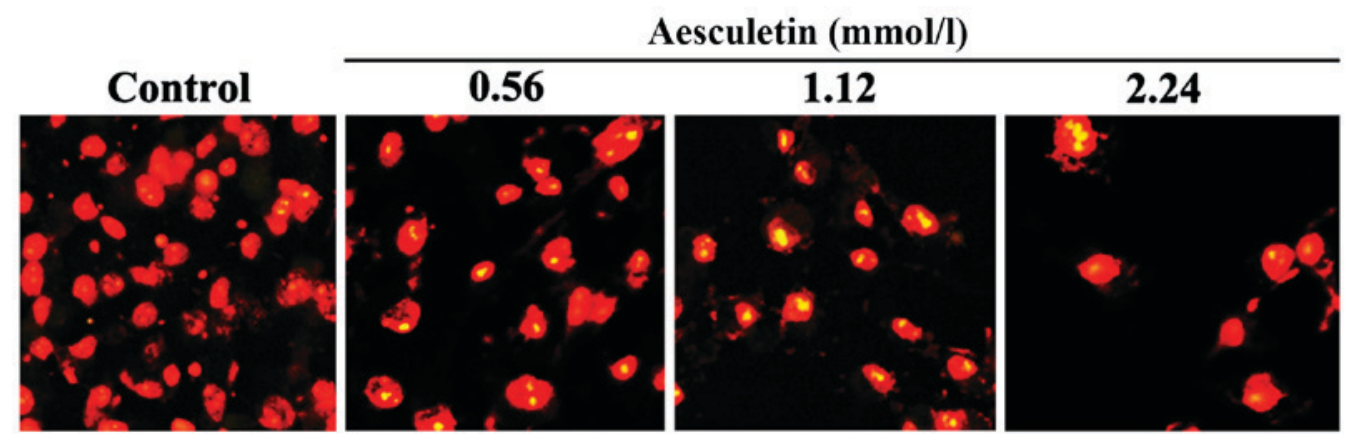

Figure 1. After $48 \mathrm{~h}$ of treatment with different concentrations of aesculetin, the number of positive cells is observed under an inverted phase microscope.

A

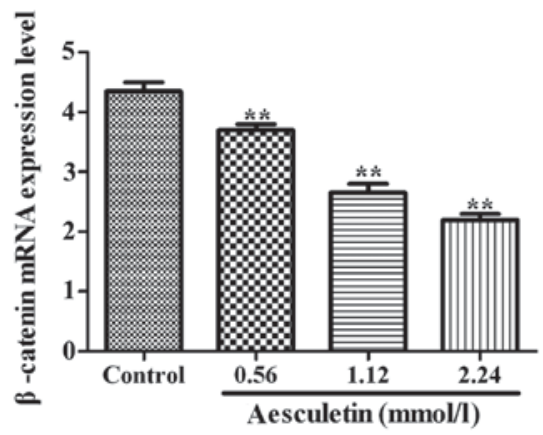

B

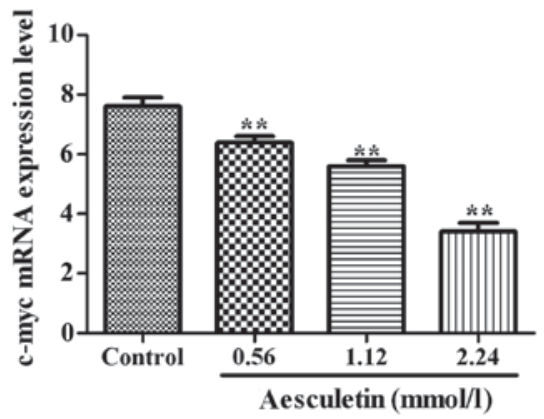

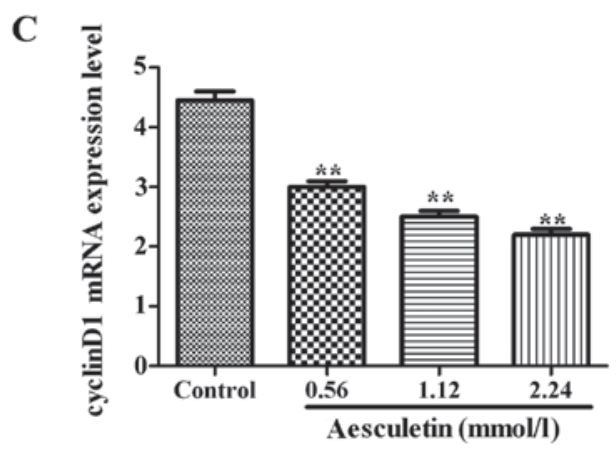

Figure 2. Reverse transcription-polymerase chain reaction (RT-PCR) is used to detect the effects of aesculetin on the expression levels of $\beta$-catenin, c-Myc and cyclin D1 mRNA in SW480 cells. Compared with those in the control group, the expression levels of $\beta$-catenin, c-Myc and cyclin D1 are significantly inhibited, ${ }^{* *} \mathrm{P}<0.01$.

Armonk, NY, USA). One-way analysis of variance (ANOVA) was used to statistically analyze data, and the post-hoc test used was SNK test. $\mathrm{P}<0.05$ was set as the statistically significant difference.

\section{Results}

Detection of the effects of aesculetin on the inhibition rate of SW480 cells by CCK-8. The proliferation of SW480 cells was significantly inhibited in each group after they were cultured in the culture medium containing $0.56,1.12$ and $2.24 \mathrm{mmol} / 1$ aesculetin for 24, 48 and $72 \mathrm{~h}$, respectively. By contrast, the proliferation inhibition rate was significantly increased with the increase of concentration and time in a significant dose-dependent manner $(\mathrm{P}<0.01)$ (Table II). In the follow-up experiments $0.56,1.12$ or $2.24 \mathrm{mmol} / \mathrm{l}$ aesculetin were selected as the concentrations of administration, and the action time was $48 \mathrm{~h}$.
Detection of the effects of aesculetin on the proliferation of SW480 cells by BrdU tests. As shown in Fig. 1, BrdU test results showed that compared with the control group, the number of BrdU-positive cells in each group was significantly different after the treatment with BrdU for the same period. The number of the aesculetin group was significantly less than that in the control group $(\mathrm{P}<0.01)$.

Effects of aesculetin on the levels of $\beta$-catenin, $c$-Myc and cyclin D1 mRNA. As shown in Fig. 2, the levels of $\beta$-catenin, c-Myc and cyclin D1 mRNA in each group were significantly inhibited compared with those in the control group after the cells were cultured in the culture medium containing $0.56,1.12$ and $2.24 \mathrm{mmol} / \mathrm{l}$ aesculetin for 24,48 and $72 \mathrm{~h}$, respectively $(\mathrm{P}<0.01)$.

Effects of aesculetin on the expression levels of $\beta$-catenin, $c$-Myc and cyclin D1 proteins. As shown in Fig. 3, the levels of $\beta$-catenin, c-Myc and cyclin D1 proteins in each group were 

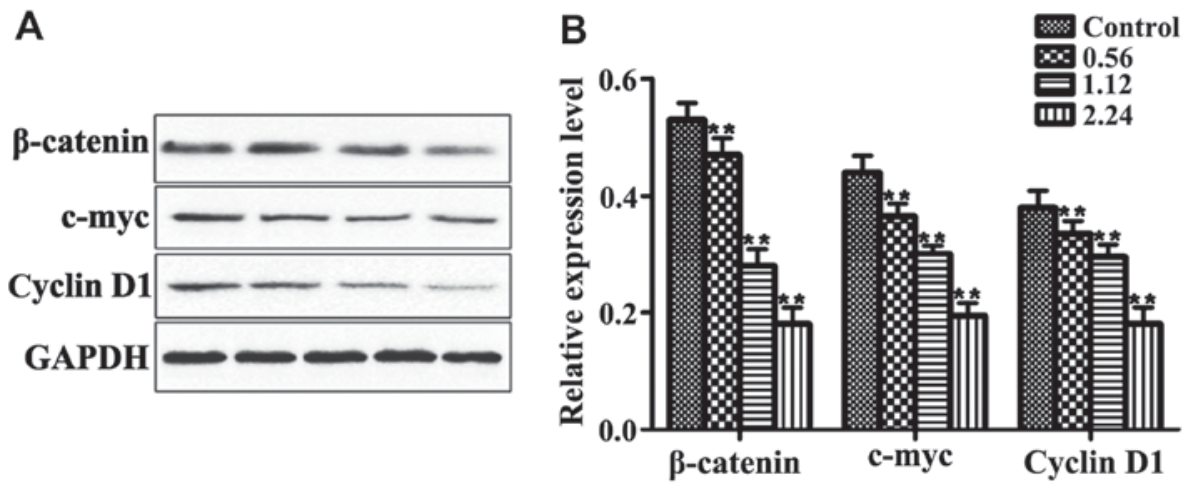

Figure 3. Western blotting is used to detect the effects of aesculetin on the expression of $\beta$-catenin, c-Myc and cyclin D1 proteins in SW480 cells. (A) $\beta$-catenin, c-Myc and cyclin D1 proteins. (B) Gray-scale analysis results of $\beta$-catenin, c-Myc and cyclin D1 proteins, ${ }^{* *} \mathrm{P}<0.01$.

Table II. Inhibitory effects of aesculetin at different concentrations on the proliferation of SW480 cells (mean \pm SD, $n=30$ ).

\begin{tabular}{lccc}
\hline \multirow{2}{*}{$\begin{array}{l}\text { Concentration } \\
(\mathrm{mmol} / \mathrm{l})\end{array}$} & \multicolumn{3}{c}{ Proliferation inhibition rate (\%) } \\
\cline { 2 - 4 } & $24 \mathrm{~h}$ & $48 \mathrm{~h}$ & $72 \mathrm{~h}$ \\
\hline Control group (0) & 0 & 0 & 0 \\
0.56 & $17.29 \pm 1.25^{\mathrm{a}}$ & $35.61 \pm 2.25^{\mathrm{a}}$ & $39.53 \pm 3.12^{\mathrm{a}}$ \\
1.12 & $26.64 \pm 1.56^{\mathrm{a}}$ & $50.12 \pm 3.32^{\mathrm{a}}$ & $60.25 \pm 2.56^{\mathrm{a}}$ \\
2.24 & $36.72 \pm 1.96^{\mathrm{a}}$ & $68.22 \pm 3.83^{\mathrm{a}}$ & $72.65 \pm 3.08^{\mathrm{a}}$ \\
\hline
\end{tabular}

Compared with the control group, ${ }^{\mathrm{a}} \mathrm{P}<0.01$.

significantly inhibited compared with those in the control group after the cells were cultured in the culture medium containing $0.56,1.12$ and $2.24 \mathrm{mmol} / \mathrm{l}$ aesculetin for 24,48 and $72 \mathrm{~h}$, respectively in a dose-dependent manner to a certain degree $(\mathrm{P}<0.01)$.

\section{Discussion}

Colon cancer is a common tumor with a high incidence rate clinically. In recent years, the number of deaths and the mortality rate of colon cancer have shown a clear upward trend both in China and other countries and regions. Colon cancer is an important factor affecting human health and life. Tumor cell metastasis or the loss of sensitivity to chemotherapeutic drugs is the leading cause of death caused by colon cancer, and the mechanisms of cell proliferation and invasion and the metastasis of colon cancer are complex and involve changes in different genes $(11,12)$.

$\beta$-catenin is an intercellular adhesion molecule. It participates in the cell adhesion on the cell membrane, but once the nucleus is translocated or degraded, its adhesion activity disappears (13). A study showed that $\beta$-catenin, not only mediates cell adhesion, but also transducts signals. The abnormal activation of $\mathrm{Wnt} / \beta$-catenin signaling pathway is one of the important mechanisms of human tumorigenesis. The overexpression of $\beta$-catenin is also the main manifestation of the activation of the signaling pathway (14). The proto-oncogenes, cyclin DI and $c-M y c$, play important roles in the process of cell proliferation, differentiation and apoptosis, and are related to the development of various tumors. In recent years, a study showed that cyclin DI and $c-M y c$ are very important target genes in the Wnt signaling pathway (15). Immunohistochemistry confirmed that the abnormal expression of cyclin D1, c-Myc and $\beta$-catenin are correlated with the activation of the Wnt signaling pathway (16). When the Wnt signaling pathway is activated, the number of $\beta$-catenin entering the nucleus is increased, further activating the expression of cyclin D1, c-Myc and other genes and promoting cell proliferation (17). In the nucleus, if $\beta$-catenin is abnormally accumulated and activates genes, $\beta$-catenin becomes an oncogene. A study indicated that $\beta$-catenin is related to the occurrence of a variety of digestive system, hematological and reproductive system tumors (18).

In this study, colon cancer cell line SW480 was added with aesculetin at different final concentrations, and 24, 48 and $72 \mathrm{~h}$ later, the indexes were detected. The results of CCK-8 showed that compared with the control group, aesculetin effectively inhibited the proliferation of SW480 cells. The BrdU test results indicated that the number of BrdU-positive cells in all the groups treated with drugs was significantly decreased. The detection results of RT-PCR suggested that aesculetin reduced the expression level of $\beta$-catenin mRNA and inhibited the expression of mRNA in Wnt signaling pathway target genes, $c-M y c$ and cyclin D1; western blotting detection results revealed that aesculetin downregulated the expression level of $\beta$-catenin, c-Myc and cyclin D1 proteins. Utsuki et al (19) analyzed the expression levels of cyclin D1 and $\beta$-catenin in tumor tissues and found that with tumor deterioration, the expression levels of cyclin D1 and $\beta$-catenin were gradually increased. In addition, Ehrlich et al (20) showed that the positive expression rates of $\beta$-catenin, cyclin D1 and c-Myc in nephroblastoma cells were significantly increased compared with those in normal renal tissues, indicating that the $\mathrm{Wnt} / \beta$-catenin signaling pathway plays an important role in the formation of nephroblastoma. Studies of $\mathrm{Hu}$ et al (21) and Liu et al (22) showed that aesculetin can reduce the level of $\beta$-catenin abnormally aggregated in tumor cells, thus inhibiting the expression of cyclin D1 and c-Myc to inhibit the growth of colon cancer cells. The results provide a theoretical basis for the therapeutic effect of aesculetin on colon cancer.

In conclusion, this study demonstrates that aesculetin can inhibit the proliferation of colon cancer cell line SW480, 
and its mechanism may be achieved by inhibiting the Wnt signaling pathway.

\section{Acknowledgements}

Not applicable.

\section{Funding}

No funding was received.

\section{Availability of data and materials}

All data generated or analyzed during this study are included in this published article.

\section{Authors' contributions}

TL contributed significantly to writing the manuscript and cell culture. LZ analyzed and interpreted CCK-8 assay. $\mathrm{XH}$ contributed significantly to manuscript preparation and BrdU test. All authors read and approved the final manuscript.

\section{Ethics approval and consent to participate}

Not applicable.

\section{Consent for publication}

Not applicable.

\section{Competing interests}

The authors declare that they have no competing interests.

\section{References}

1. Siegel R, Desantis C and Jemal A: Colorectal cancer statistics, 2014. CA Cancer J Clin 64: 104-117, 2014.

2. Siegel RL, Miller KD and Jemal A: Cancer Statistics, 2015. CA Cancer J Clin 65: 5-29, 2015.

3. Olaku O and White JD: Herbal therapy use by cancer patients: A literature review on case reports. Eur J Cancer 47: 508-514, 2011.

4. Wang CJ, Hsieh YJ, Chu CY, Lin YL and Tseng TH: Inhibition of cell cycle progression in human leukemia HL-60 cells by esculetin. Cancer Lett 183: 163-168, 2002.

5. Chu CY, Tsai YY, Wang CJ, Lin WL and Tseng TH: Induction of a poptosis by esculetin in human leukemia cells. Eur J Pharmacol 416: 25-32, 2001.

6. Kuo HC, Lee HJ, Hu CC, Shun HI and Tseng TH: Enhancement of esculetin on Taxol-induced apoptosis in human hepatoma HepG2 cells. Toxicol Appl Pharmacol 210: 55-62, 2006.

7. Leung KN, Leung PY, Kong LP and Leung PK: Immunomodulatory effects of esculetin (6,7-dihydroxycoumarin) on murine lymphocytes and peritoneal macrophages. Cell Mol Immunol 2: 181-188, 2005.
8. Kaneko T, Tahara S and Takabayashi F: Inhibitory effect of natural coumarin compounds, esculetin and esculin, on oxidative DNA damage and formation of aberrant crypt foci and tumors induced by 1,2-dimethylhydrazine in rat colons. Biol Pharm Bull 30: 2052-2057, 2007.

9. Noguchi M, Earashi M, Minami M, Miyazaki I, Tanaka M and Sasaki T: Effects of piroxicam and esculetin on the MDA-MB-231 human breast cancer cell line. Prostaglandins Leukot Essent Fatty Acids 53: 325-329, 1995.

10. Effect of esculetin on proliferation of human heptocellular carcinoma cell line SMMC-7721 in vitro. Chin JMAP 26: 6439-442, 2009.

11. Din FV, Theodoratou E, Farrington SM, Tenesa A, Barnetson RA, Cetnarskyj R, Stark L, Porteous ME, Campbell H and Dunlop MG: Effect of aspirin and NSAIDs on risk and survival from colorectal cancer. Gut 59: 1670-1679, 2010.

12. Tavazoie SF, Alarcón C, Oskarsson T, Padua D, Wang Q, Bos PD, Gerald WL and Massagué J: Endogenous human microRNAs that suppress breast cancer metastasis. Nature 451: 147-152, 2008.

13. Miyoshi K and Hennighausen L: Beta-catenin: A transforming actor on many stages. Breast Cancer Res 5: 63-68, 2003.

14. Maruyama K, Ochiai A, Akimoto S, Nakamura S, Baba S, Moriya Y and Hirohashi S: Cytoplasmic beta-catenin accumulation as a predictor of hematogenous metastasis in human colorectal cancer. Oncology 59: 302-309, 2000.

15. Polakis P: Wnt signaling and cancer. Genes Dev 14: 1837-1851, 2000.

16. Koehler A, Schlupf J, Schneider M, Kraft B, Winter C and Kashef J: Loss of Xenopus cadherin-11 leads to increased Wnt/beta-catenin signaling and up-regulation of target genes c-myc and cyclin D1 in neural crest. Dev Biol 383: 132-145, 2013.

17. Lim SC and Lee MS: Significance of E-cadherin/ $\beta$-catenin complex and cyclin D1 in breast cancer. Oncol Rep 9: 915-928, 2002.

18. Roh MS, Hong SH, Jeong JS, Kwon HC, Kim MC, Cho SH, Yoon $\mathrm{JH}$ and Hwang TH: Gene expression profiling of breast cancers with emphasis of beta-catenin regulation. J Korean Med Sci 19: 275-282, 2004.

19. Utsuki S, Sato Y, Oka H, Tsuchiya B, Suzuki S and Fujii K: Relationship between the expression of E-, N-cadherins and beta-catenin and tumor grade in astrocytomas. J Neurooncol 57: 187-192, 2002.

20. Ehrlich D, Bruder E, Thome MA, Gutt CN, von Knebel Doeberitz M, Niggli F, Perantoni AO and Koesters R: Nuclear accumulation of beta-catenin protein indicates activation of wnt signaling in chemically induced rat nephroblastomas. Pediatr Dev Pathol 13: 1-8, 2010.

21. Hu Y, Wang S, Wu X, Zhang J, Chen R, Chen M and Wang Y: Chinese herbal medicine-derived compounds for cancer therapy: A focus on hepatocellular carcinoma. J Ethnopharmacol 149: 601-612, 2013.

22. Liu YZ, Wu K, Huang J, Liu Y, Wang X, Meng ZJ, Yuan SX, Wang DX, Luo JY, Zuo GW, et al: The PTEN/PI3K/Akt and Wnt $/ \beta$-catenin signaling pathways are involved in the inhibitory effect of resveratrol on human colon cancer cell proliferation. Int J Oncol 45: 104-112, 2014.

This work is licensed under a Creative Commons Attribution-NonCommercial-NoDerivatives 4.0 International (CC BY-NC-ND 4.0) License. 